\title{
Pattern of carbon dioxide stimulated breathing in patients with chronic airway obstruction
}

\author{
CHRISTOPHER S GARRARD AND DONALD J LANE
}

From the Section of Pulmonary Medicine, Department of Medicine, University of Illinois at the Medical Center, Chicago, Illinois, USA, and Department of Chest Diseases, Churchill Hospital, Oxford

ABSTRACT The pattern of stimulated breathing during carbon dioxide inhalation was studied in a group of 21 patients with severe irreversible airways obstruction (mean $\mathrm{FEV}_{1}=0.9$ litre, mean $\mathrm{FEV}_{1} / \mathrm{FVC}^{\circ}=50 \%$ ). Carbon dioxide rebreathing experiments were performed, the ventilatory response being defined in terms of total ventilation $(\dot{V})$ and $\mathrm{CO}_{2}$ sensitivity $(\mathbf{S})$. Breathing pattern was defined by the changes in tidal volume $(\Delta \mathrm{VT})$ and respiratory frequency $(\Delta \mathrm{f})$ and the maximum VT achieved (VTmax). Contrary to some previous studies no significant relationship could be demonstrated between the severity of airway obstruction $\left(\mathrm{FEV}_{1} / \mathrm{FVC} \%\right.$, Raw) and the ventilatory response to rebreathing ( $\dot{\mathrm{V}}, \mathrm{S}, \Delta \mathrm{VT}, \Delta \mathrm{f}, \mathrm{VTmax})$. However, measurements of dynamic lung volume $\left(\mathrm{FEV}_{1}, \mathrm{FVC}, \mathrm{IC}\right)$ were found to be significantly correlated with the breathing pattern variables $\left(\Delta \mathrm{VT}, \Delta \mathrm{f}\right.$, VTmax). Resting $\mathrm{PaO}_{2}$ and $\mathrm{PacO}_{2}$ were significantly correlated with $\Delta \mathrm{VT}$ but not $\Delta \mathrm{f}$. Results indicate that the degree of airway obstruction does not dictate the ventilatory or breathing pattern response to carbon dioxide induced hyperpnoea. In contrast it is the restriction of dynamic lung volume, by limiting the $\mathrm{V}_{\mathrm{T}}$ response, that appears to determine the ventilatory and breathing pattern response in patients with severe airway obstruction.

A reduced total ventilatory response to $\mathrm{CO}_{2}$ in patients with chronic airway obstruction has long been recognised ${ }^{1}$; however, surprisingly little attention has been paid to the pattern of breathing.

In recent years considerable progress has been made in understanding the factors controlling tidal volume (VT) and breath intervals (total breath duration $\mathrm{Tt}$, inspiratory duration $\mathrm{Ti}$, and expiratory duration $\mathrm{Te}$, in experimental animals and in normal man. ${ }^{23}$ It is, therefore, a logical step to consider the impaired ventilatory response in patients with chronic airways obstruction in terms of abnormalities in breathing pattern.

\section{Methods}

Twenty-one male patients with severe, chronic, irreversible, airway obstruction underwent $\mathrm{CO}_{2}$ rebreathing experiments. ${ }^{4}$ Each patient gave full informed consent. The presence of airway obstruc-

Address for reprint requests: Dr CS Garrard, Section of Pulmonary Medicine, University of Illinois at the Medical Centre, $840 \mathrm{~S}$ Wood Street, Chicago, Illinois 60680, USA. tion was defined as a reduction in the absolute $\mathrm{FEV}_{1}$ to less than $50 \%$ predicted value, and $\mathrm{FEV}_{1} / \mathrm{FVC}^{2} \%$ less than $60 \%$. No significant reversibility of airway obstruction $(<15 \%$ change in $\mathrm{FEV}_{1}$ ) could be obtained by the inhalation of aerosolised isoprenaline.

After an initial rest period, subjects were allowed to rebreathe a mixture of $7 \% \mathrm{CO}_{2}$ in $93 \% \mathrm{O}_{2}$ contained within a six-litre anaesthetic bag. The rebreathing bag was connected via a three-way tap to a heated Fleisch (no 3) pneumotachograph and rubber mouthpiece. The tap was turned so as to connect with either ambient air or the rebreathing mixture. The resistance of the rebreathing circuit was $0.025 \mathrm{kPa} \mathrm{l}^{-1} \mathrm{~s}\left(0.25 \mathrm{cmH}_{2} \mathrm{O}^{-1} \mathrm{~s}\right)$.

Rebreathing was continued to the limit of tolerance determined by the patient or when the inspired $\mathrm{CO}_{2}$ level reached $10 \%$. After reaching the limit of tolerance the patient was again allowed to breathe air. Rebreathing times ranged between four and six minutes between individuals.

Airflow, its integral, tidal volume (VT) and end-tidal $\mathrm{CO}_{2}$ concentration $\left(\mathrm{PETCO}_{2}\right)$ were re- 
corded on a multichannel linear recorder (Brush, Gould Instruments). Calibration of the pneumotachograph volume signal was performed beiore and after each procedure using a one-litre displacement syringe. The accuracy of the pneumotachograph was confirmed using air, the initial rebreathing mixture, and a mixture equivalent to that achieved at the end of rebreathing. No significant differences in volume calibration could be demonstrated between these gas mixtures.

Values of VT, breath intervals ( $\mathrm{Ti}$ and $\mathrm{Te}$ ), and $\mathrm{PeTCO}_{2}$ were measured by hand from the linear record. Breathing pattern was represented as the breath by breath plot of $\mathrm{VT}$ against $\mathrm{Ti}$ and $\mathrm{Te}$ (figure). Lines of best fit were drawn by hand through each plot so as to pass through the mean values for five initial and final breaths. This ensured that the mean values of $\mathrm{VT}, \mathrm{Ti}$ and $\mathrm{Te}$ used in the statistical analyses were representative of each subject's breathing pattern. Values of

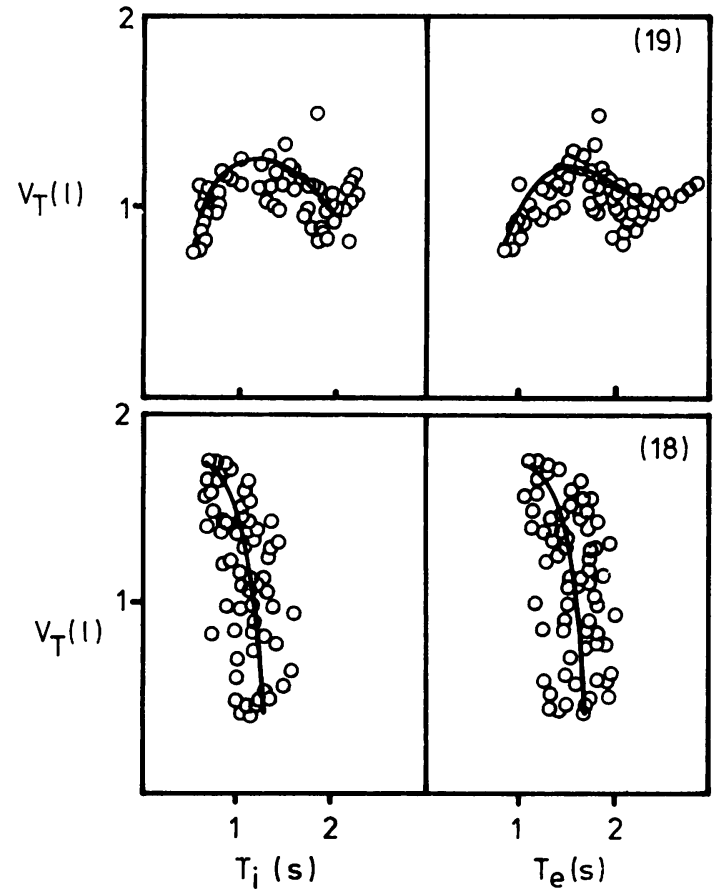

Figure Examples of breathing pattern plots in two of the patients studied as described by the tidal volume/ breath interval $(T i, T e)$ relationship. Each symbol represents a single breath, some having been omitted for clarity. The example on the top shows little increase in $V T$ but significant shortening of both $T i$ and $T e$ (that is, increase in respiratory frequency) while below the increase in ventilation is achieved mostly by an increase in $V T$. respiratory frequency and the changes in respiratory frequency $(\Delta f)$ were derived from the values of Ti and Te.

Statistical analysis of group mean data was made using Student's $t$ test, linear regressions by least squares regression analysis. SI units are quoted with standard units in parentheses. Conversion of $\mathrm{mmHg}$ (torr) to $\mathrm{kPa}$ requires a multiplication factor of 0.133 ; for $\mathrm{cmH}_{2} \mathrm{O}$ to $\mathrm{kPa}$, a factor of $0 \cdot 1$.

Forced expiratory volume in one second $\left(\mathrm{FEV}_{1}\right)$, forced vital capacity (FVC), inspiratory capacity (IC), functional residual capacity (FRC), and airways resistance (Raw) were measured using a constant volume whole body plethysmograph (Fenyves and Gut; Basle, Switzerland). For Raw estimation, subjects breathe warm, moist air fulfilling BTPS conditions. ${ }^{56}$ Measurements were made during resting breathing so that panting manoeuvres were avoided.

Blood gas analysis was made immediately after radial artery blood sampling using Radiometer equipment.

\section{Results}

Anthropometric and physiological characteristics of the 21 patients with airway obstruction are given in table 1 . The severity of the airway obstruction is indicated by the group mean $\mathrm{FEV}_{1}=$ 0.931 representing $50 \%$ of mean FVC. Mean Raw (inspiratory) for the group was $0.65 \mathrm{kPa}^{-1} \mathrm{~s}$ $\left(6.5 \mathrm{cmH}_{2} \mathrm{O} \mathrm{l}^{-1} \mathrm{~s}\right)$. Upper limit of adult value for our laboratory, $0.2 \mathrm{kPa} \mathrm{l}^{-1} \mathrm{~s}\left(2 \mathrm{cmH}_{2} \mathrm{O} \mathrm{l}^{-1} \mathrm{~s}\right)$. No relationship could be demonstrated $(\mathrm{p}<0.1)$ between either the spirometric $\left(\mathrm{FEV}_{1} / \mathrm{FVC}\right)$ or the plethysmographic (Raw) parameters of airway

Table 1 Anthropometric and physiological data of the 21 patients studied. Values expressed as the mean $\pm 1 S D$

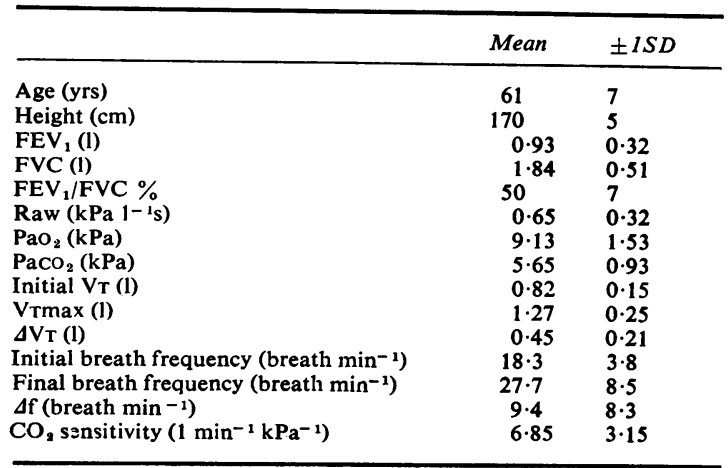


obstruction, and any of the indices chosen to represent total ventilatory ( $\mathrm{Vmax}) \mathrm{CO}_{2}$ sensitivity $\left(\mathrm{SV} / \mathrm{PCO}_{2}\right)$ or pattern response to $\mathrm{CO}_{2}(\Delta \mathrm{VT}, \Delta \mathrm{F}$, VTmax).

In contrast individual volumes $\left(\mathrm{FEV}_{1} \mathrm{FVC}\right.$, and IC) showed varying but significant degrees of correlation with the indices of breathing pattern response (table 2 ), reduction in lung volumes being associated with diminished response to $\mathrm{CO}_{2}$. Although resting $\mathrm{PaO}_{2}$ and $\mathrm{PaCO}_{2}$ were found to be significantly correlated with $\Delta V T \quad(p<0.05$ and $\mathrm{p}<0.01$ respectively) no corresponding correlation was demonstrated with $\Delta$ f (table 2).

Table 2 Correlations of breathing pattern indices $(\Delta V T, \Delta f, V T$ max $)$ with physiological variables of the 21 patients with chronic airway obstruction

\begin{tabular}{|c|c|c|c|c|}
\hline & $\begin{array}{l}F E V_{1} \\
(I)\end{array}$ & $\begin{array}{l}F V C \\
(l)\end{array}$ & $\begin{array}{l}\mathrm{PaO}_{2} \\
(k P a)\end{array}$ & $\begin{array}{l}\mathrm{PaCO}_{2} \\
(k P a)\end{array}$ \\
\hline$\Delta \mathrm{VT}_{\mathrm{T}}(\mathrm{l})$ & $\begin{array}{l}r=0.80 \\
p<0.001\end{array}$ & $\begin{array}{l}r=0.81 \\
\mathrm{p}<0.001\end{array}$ & $\begin{array}{l}r=0.48 \\
p<0.05\end{array}$ & $\begin{array}{l}r=-0.58 \\
p<0.01\end{array}$ \\
\hline$\Delta f\left(\right.$ breaths min $^{-1}$ ) & $\begin{array}{l}r=-0.37 \\
(N S)\end{array}$ & $\begin{array}{l}r=-0.45 \\
p<0.05\end{array}$ & $\begin{array}{l}r=0.07 \\
(\mathrm{NS})\end{array}$ & $\begin{array}{l}r=0.16 \\
(N S)\end{array}$ \\
\hline VTmax (l) & $\begin{array}{l}\mathrm{r}=0.63 \\
\mathrm{p}<0.01\end{array}$ & $\begin{array}{l}\mathrm{r}=0.69 \\
\mathrm{p}<0.001\end{array}$ & $\begin{array}{l}r=0.09 \\
\text { (NS) }\end{array}$ & $\begin{array}{l}r=0.37 \\
(N S)\end{array}$ \\
\hline
\end{tabular}

\section{Discussion}

After the work of early investigators into $\mathrm{CO}_{2}$ responsiveness in chronic bronchitis and emphysema, ${ }^{178}$ some authorities considered the mechanical impedance afforded by the airway obstruction to be of prime importance in diminishing ventilatory response to $\mathrm{CO}_{2}, 9{ }^{10}$ while others attributed this to an impaired CNS sensitivity to $\mathrm{CO}_{2}{ }^{11-14}$ The inter-relationships of these two mechanisms were investigated and clarified by Lourenço and Miranda ${ }^{15}$ and Lane et al. ${ }^{16}$ If mechanical factors alone are important, some correlation should be demonstrable betwen ventilatory response and indices reflecting the impaired mechanical status of the lungs, especially those relating to the degree of airway obstruction. Unlike other studies, ${ }^{17-19}$ we were unable to demonstrate a significant relationship between $\mathrm{CO}_{2}$ sensitivity (S) and the pulmonary function assessment of airway obstruction.

Our studies demonstrate that the diminished ventilatory response is caused primarily by the small VTmax values achieved, the higher respiratory frequencies failing to compensate sufficiently for these lower volumes. The markedly reduced VT response to respiratory stimuli in patients with chronic airway obstruction does not initially appear to be unexpected especially in view of the greatly impaired total ventilatory response. In the early study by Scott $^{7}$ the largest VT achieved by any of his subjects was $860 \mathrm{ml}$, and this diminished VT response in patients with airway obstruction has subsequently been noted by several groups of workers. ${ }^{20-21}$ Sorli et $a l^{22}$ have proposed that it is only patients who have a lower than normal resting VT who develop $\mathrm{CO}_{2}$ retention. ${ }^{22}$ However no data were obtained during respiratory stimulation to obtain values of VTmax.

Although the degree of airway obstruction did not correlate with total ventilatory or pattern responses to $\mathrm{CO}_{2}$ rebreathing, individual volumes $\left(\mathrm{FEV}_{1}, \mathrm{FVC}, \mathrm{IC}\right)$ correlated well. This was particularly true for VT which showed the strongest correlations with absolute values $F_{1} V_{1}$ and FVC. It may, therefore, be deduced that the mechanical constraints on the lungs determining VT are of a restrictive rather than an obstructive nature.

Mean VTmax responses at the end of maximum tolerated levels of inspired $\mathrm{PCO}_{2}$ reached a volume which represented $60 \%$ of $\mathrm{VC}$, a somewhat higher value than that obtained by Potter et $a l^{21}$ and similar to the results obtained by Lane. ${ }^{23}$ In rebreathing studies in normal subjects ${ }^{24}$ we have shown VTmax never to be greater than IC and though VTmax exceeded IC in three subjects in the present study this was only by small volumes $(50 \mathrm{ml})$, which probably fall within the experimental error of the measurements. Endexpiratory lung volumes (FRC) do not remain fixed during stimulated breathing in patients with airway obstruction, FRC increasing significantly. ${ }^{25-27}$ This increase in static lung volume together with the increase in VT may result, therefore, in tidal excursions actually exceeding TLC during hyperpnoea.

Increased respiratory frequency in patients with obstructive lung disease has long been recognised. Rheinhardt ${ }^{7}$ recorded high resting respiratory frequencies (mean 23 breaths min $^{-1}$ ). Scott $^{6}$ found a similar relationship (18 breaths min $^{-1}$ for patients with airway obstruction and 12.5 breaths min $^{-1}$ for normal subjects). Our own data in normal subjects ${ }^{24}$ likewise show a lower resting frequency $(13.9$ breath $\min ^{-1}$ ) than that found here in patients with airway obstruction (18.3 breaths $\left.\mathrm{min}^{-1}\right)$.

This increased frequency of breathing at rest in patients with chronic airway obstruction contrasts with the slow deep breathing observed at rest in normal people subjected to non-elastic loading of expiration. ${ }^{28} 29$ Mechanical considerations suggest that slowing the rate of respiration is more economical in terms of respiratory work in the face of airway obstruction than increasing 
the rate. In pathological intrapulmonary airway obstruction it seems that this pattern is abandoned for an apparenly inefficient mode of rapid shallow breathing. The present data confirm that this discrepancy is even more marked during ventilatory stimulation.

Since this response appears to be inappropriate in purely mechanical terms there may be other factors involved in the tachypnoea. Lung conditions characterised by a resistive defect have disproportionately high respiratory frequencies at rest or during exercise. This is observed for example in mitral stenosis, ${ }^{30}$ pulmonary fibrosis, ${ }^{31}{ }^{32}$ and pneumothorax. ${ }^{33}$ Is there then a restrictive component influencing breathing pattern in patients with chronic airflow obstruction? This could be so if "restrictive" is interpreted not in the accepted sense of stiff lungs with reduced lung volumes but as a loss of compliance associated with breathing at high lung volume. Apart from the purely mechanical problems of breathing at high lung volumes, associated reflex phenomena involving lung stretch receptors may also be implicated in the production of tachypnoea.

Recently it has been shown that patients with chronic obstructive lung disease who were hypoxic achieved higher respiratory frequencies than those who were not. ${ }^{34}$ A similar trend was seen in the relationship of $\Delta \mathrm{f}$ and $\mathrm{PaO}_{2}$ from our data, but this negative correlation was not significant. Unlike the data presented here, Bradley et al $^{34}$ were unable to demonstrate any differences in $\mathrm{FEV}_{1}$ between the hypoxic patients with higher respiratory frequencies and those breathing more slowly. Arterial blood gases were seen to be better (higher $\mathrm{PaO}_{2}$, lower $\mathrm{PaCO}_{2}$ ) in our subjects with the largest VT values. This may be an inevitable correlation because of the superior pulmonary function values in these subjects, but on the other hand may reflect the lower $V_{D} / V_{T}$ ratio associated with larger values of VT.

Our findings would suggest therefore that, although the ventilatory response to $\mathrm{CO}_{2}$ rebreathing in severe airway obstruction is not directly related to the degree of obstructive pulmonary function impairment, the breathing pattern components are dependent on lung mechanics. In particular, the maximum increase in VT appears to be closely related to the restriction of dynamic lung volumes.

\section{References}

1 Rheinhardt $\mathrm{R}$. Über das Verhältnis von $\mathrm{CO}_{-}-$ Ausr chiendung zur Atemgrösse beim lungen em- physem. Deutsch Arch Klin Med 1912; 109:192208.

2 Clark FJ, Euler CV. The regulation of depth and rate of breathing. J Physiol (London) 1972; 222: 267-91.

3 Gardner WN. The relationship between tidal volume and inspiratory and expiratory times during steady-state carbon dioxide inhalation in man. J Physiol (Lond) 1977; 272:591-611.

4 Read DJC, Leigh J. Blood brain tissue $\mathrm{PCO}_{2}$ relationships and ventilation during rebreathing. J Appl Physiol 1967; 23:53-70.

5 DuBois AB, Botelho SY, Comroe JH. A new method for measuring airways resistance in man using a body plethysmograph: values in normal subjects and in patients with respiratory disease. J Clin Invest 1965; 35:327-35.

6 Jaeger MJ, Bouhuys A. Loop formation in pressure vs flow diagrams obtained by body plethysmographic techniques. Progr Respir Res 1969; 4:116-30.

7 Scott RW. Observations on the pathologic physiology of chronic pulmonary emphysema. Arch Intern Med 1920; 26:544-60.

8 Donald KW, Christie RV. The respiratory response to carbon dioxide and anoxia in emphysema. Clin Sci 1949; 8:33-44.

9 Richards DW, Fritts HW, Davis AL. Observations on the control of respiration in emphysema: the effect of oxygen on ventilatory response to $\mathrm{CO}_{2}$ inhalation. Trans Assoc Am Physicians 1958; 71:142-51.

10 Brodovsky D, MacDonnell JA, Cherniack RM. The respiratory response to $\mathrm{CO}_{2}$ in health and in emphysema. J Clin Invest 1960; 39:724-9.

11 Prime FJ, Westlake EK. The respiratory response to $\mathrm{CO}_{2}$ in emphysema. Clin Sci 1954; 13:321-32.

12 Alexander JK, West JR, Wood JA, Richards DW. Analysis of respiratory response to carbon dioxide inhalation in varying clinical states of hypercapnia, anoxia and acid base derangement. J Clin Invest 1955; 34:511-32.

13 Fishman AP, Samet P, Cournand A. Ventilation drive in chronic pulmonary emphysema. $A m J$ Med 1955; 19:533-48.

14 Park SS. Factors responsible for carbon dioxide retention in chronic obstructive lung disease. $A m$ Rev Respir Dis 1965; 92:245-54.

15 Lourenço RV, Miranda JM. Drive and performance of the ventilatory apparatus in chronic obstructive lung disease. $N$ Engl J Med 1968; 279: 53-9.

16 Lane DJ, Howell JBL, Giblin B. Relation between airways obstruction and $\mathrm{CO}_{2}$ tension in chronic obstructive airways disease. $\mathrm{Br}$ Med J 1968; 3: 707-9.

17 Clark TJH. The ventilatory response to $\mathrm{CO}_{2}$ in chronic airways obstruction measured by a rebreathing method. Clin Sci 1968; 34:559-68.

18 King TKC, Yu D. Factors determining the ventilatory response to carbon dioxide in chronic 
obstructive airways disease. Clin Sci 1970; 39: $653-62$.

19 Ingram RH, Miller RB, Tate LA. Ventilatory response to carbon dioxide and to exercise in relation to the pathophysiologic type of chronic obstructive pulmonary disease. Am Rev Respir Dis 1972; 105:541-51.

20 Pierce AK, Luterman D, Loudermilk J, Blomqvist G, Johnson RL. Exercise ventilatory patients in normal subjects and patients with airway obstruction. J A ppl Physiol 1968; 25:1249-54.

21 Potter WA, Olafsson S, Hyatt RE. Ventilatory mechanics and expiratory flow limitation during exercises in patients with obstructive lung disease. $J$ C'lin Invest 1971; 50:910-9.

22 Sorli J, Grassino A, Lorange G, Milic-Emili J. Control of breathing in patients with chronic obstructive lung disease. Clin Sci 1978; 54:295304.

23 Lane DJ. The regulation of ventilation in chronic airways obstruction. MD thesis. Oxford, 1970.

24 Garrard CS, Lane DJ. The pattern of stimulated breathing in man during non-elastic expiratory loading. J Physiol (Lond) 1978; 279:12-29.

25 Leaver DG, Pride NB. Ventilatory adaptation to expiratory airflow obstruction: place of breathing exercises. Thorax 1974; 29:610.

26 Garrard CS. Factors influencing breathing pattern in chronic airflow obstruction. DPhil thesis.
Oxford, 1978

27 Garrard CS, Lane DJ. The pattern of breathing in chronic airflow obstruction. Clin Sci 1979; 56:215-21.

28 McIlroy MD, Eldridge RL, Thomas JP, Christie $R V$. The effect of added elastic and non-elastic resistance in the pattern of breathing in normal subjects. Clin Sci 1956; 15:337-44.

29 Zechman F, Hall FG, Hull WE. Effects of graded resistance to tracheal airflow in man. J Appl Physiol 1957; 10:356-62.

30 Marshall R, McIlroy MD, Christie RV. The work of breathing in mitral-stenosis. Clin Sci 1954; 13: $137-46$.

31 West JR, Alexander JK. Studies on respiratory mechanics and the work of breathing in pulmonary fibrosis. Am J Med 1959; 27:529-44.

32 Kaltreider NL, McCann WS. Respiratory response during exercise in pulmonary fibrosis and emphysema. J Clin Invest 1937; 16:23-40.

33 Cotes JE, Johnson CR, McDonald A. Breathing frequency, tidal volume and breathlessness. In: Porter R (ed). Breathing. Hering-Breuer Centenary Symposium. London: Churchill, 1970: 297-314.

34 Bradley CA, Fleetham JA, Anthonisen NR. Ventilatory control in patients with hypoxemia due to obstructive lung disease. Am Rev Respir Dis 1979; 120:21-30. 